\title{
Violência no Brasil à luz dos relatórios das Conferências Nacionais de Saúde (2000-2019)
}

\section{Violence in Brazil in view of the reports of the National Health Conferences (2000-2019)}

\section{Thaís Kristosch Imperatori', Melina Sampaio de Ramos Barros ${ }^{2}$}

1. Graduada em Serviço Social e Ciências Sociais pela Universidade de Brasília (UnB). Especialista em Educação e Promoção da Saúde pela UnB. Mestre e doutora em Política Social pela mesma instituição, com período de sanduíche na Universitat de Barcelona - Espanha. É professora adjunta do Departamento de Serviço Social da UnB. Orcid: 0000-0003-4536-5698. thaisimperatori@unb.br

2. Graduada em Serviço Social pela Universidade de Brasília (UnB). Mestre e doutoranda em Política Social pela UnB. Orcid: 0000-0002-8160-2067. melina_barros@hotmail.com

Resumo: A saúde coletiva se coloca como importante campo de pesquisas sobre violência, que propõe ações de prevenção e enfrentamento a esse determinante social de saúde. O presente artigo analisa como diversas expressões da violência têm sido historicamente debatidas e apresentadas nos relatórios das Conferências Nacionais de Saúde (CNs), espaço privilegiado de participação social para a definição de prioridades e diretrizes da Política. Para tanto, foi realizada uma análise documental dos relatórios das CNS a partir do ano 2000, quando se aprofundam as discussões sobre violência e saúde nesse espaço público. Os dados apontam para a crescente incorporação da temática, apresentada como uma das principais causas de mortalidade e morbidade da 
população brasileira. Em quase todos os relatórios, a violência foi colocada enquanto problema de saúde pública e progressivamente foram incorporados temas específicos com destaque para a violência contra mulher, a violência no contexto da saúde mental e a violência contra crianças e adolescentes, caracterizando a especialização na abordagem da temática.

Palavras-chave: Violência; Saúde; Conferência Nacional de Saúde; Controle social; Participação social.

Abstract: The collective health places itself as an important field of research about violence, that propose actions of prevention and confrontation of this social determinant of health. The present paper analyzes how diverse expressions of violence have been historically debated and presented in the reports of National Health Conferences (NHC), a privileged space of social participation to the definition of priorities and guidelines of the Policy. For this purpose, a documental analysis of reports from the NHC since the year 2000 has been conducted, when discussions about violence and health were deepened in this public space. The data points to the crescent embedding of the subject presented as one of the main causes of mortality and morbidity in the Brazilian population. In almost all the reports, violence has been raised as a public health problem and progressively incorporating specific themes focusing on violence against women, violence in the context of mental health, and violence against children and adolescents.

Keywords: Violence; Health; National Health Conferences; Social control; Social participation.

\section{Introdução}

A violência enquanto categoria conceitual é permeada por definições polissêmicas, heterogêneas e contraditórias. Sem demarcação quanto ao seu surgimento e natureza única, entende-se a violência como um fenômeno de caráter estruturante na sociedade moderna, com dinâmica psicossocial, individual e coletiva (oliveıra, 2018). Dessa forma, a violência se constitui de maneira ampla, dando margem para diferentes tipologias e caracterizações 
sobre as suas motivações e fundamentos básicos, como a violência institucional, ideológica, física e moral baseadas em relações hierárquicas de poder. Segundo Minayo e Souza (1997), o problema da violência precisa ser compreendido a partir de aspectos macroestruturais e conjunturais próprios da desigualdade. Entendê-la em uma definição fixa e simples pode gerar uma compreensão equivocada e deslocada da especificidade histórica, por isso se constitui como um fenômeno sócio-histórico que resulta de múltiplas determinações.

$\mathrm{Na}$ qualidade de problema social e público, a violência envolve diversos atores para a gestão do seu enfrentamento, assim como da sua reprodução. $\mathrm{O}$ debate sobre os índices de violência no contexto brasileiro perpassa as esferas do Estado e da sociedade civil, demandando políticas e serviços públicos para o seu monitoramento, prevenção, controle e enfrentamento. Assim, a violência é marcada por sua intersetorialidade, não é em si mesma uma questão de saúde. Ela só passa a ser problematizada na área à medida que afeta a saúde individual e coletiva e exige a organização de políticas, programas e práticas específicas a determinadas demandas (MINAYo, 2006A). De modo geral, a violência atinge o contexto de saúde em relação às vítimas da violência, bem como as causas que formam contextos de violência.

A saúde pública, como campo de produção do conhecimento e intervenção na realidade, é demarcada por se preocupar com o bem-estar da população e seu desenvolvimento social. Isso significa não se limitar a recuperar indivíduos doentes ou vítimas de traumas, mas compreender que o impacto da violência na saúde vai além da saúde física, psicológica e sexual das vítimas e gera efeitos sociais e impactos no desenvolvimento (CONCHA-EASTMAN; MALO, 2007). Além disso, são consideradas as possibilidades de atuação da saúde pública para a prevenção e controle das violências, que associada a outras políticas públicas podem gerar impactos positivos para a sociedade.

Com efeito, é necessário problematizar as violências no campo da saúde para além do atendimento específico a lesões, traumas e mortes. De acordo com Minayo e Souza (1997), a compreensão das violências exige o reconhecimento da complexidade e controvérsia do objeto. Isso implica uma leitura da realidade a partir de múltiplas violências de acordo com os diferentes contextos 
e circunstâncias. Nesse sentido, a política de saúde pode liderar ações específicas, intersetoriais e de militância cidadã de modo a promover qualidade de vida, ambiente saudável, luta por direitos e superação de situações de dominação, exclusão e violência, além da prevenção de agravos e riscos na atenção e recuperação de vítimas de violência e acidentes.

Esse entendimento à violência contempla o conceito ampliado de saúde: não apenas como ausência de doença, mas como situação de bem-estar físico, mental e social. Essa compreensão foi incorporada na Lei Federal no 8.080/90, que regulamenta a saúde como direito fundamental ao ser humano e com diversos fatores determinantes e condicionantes sociais como alimentação, moradia, saneamento básico, meio ambiente, trabalho, renda, educação, transporte, lazer, acesso a bens e serviços essenciais, entre outros. Desse modo, considera-se que as violências também podem ser interpretadas como determinantes sociais de ausência de saúde no seu sentido ampliado, na medida em que geram impactos de morbimortalidade e alteram situações de bem-estar.

No contexto internacional, diversas resoluções do Conselho Diretor da Organização Pan-Americana de Saúde (opAs) ${ }^{1}$, vinculada à Organização Mundial de Saúde (oms) ${ }^{2}$, reiteram o entendimento da violência como questão de saúde pública. Desde 1993, ano de formulação do Primeiro Plano de Prevenção Regional da Violência, estas organizações entendem a violência, em todas as suas manifestações, como uma prioridade de saúde devido à ameaça ao desenvolvimento dos povos, ao seu impacto na qualidade de vida e ao desgaste gerado para o tecido social. Como direção aos Estados nacionais signatários,

1. A OPAS é um organismo internacional que funciona regionalmente como setor especializado no trato sobre saúde nas Américas. Atua no monitoramento, cooperação e direção de normativas de saúde a partir da realidade da região e da perspectiva da OMS. Foi fundada no início do século XX, em 1902, se configurando como uma organização especializada e de respaldo aos Estados nacionais da região.

2. A OMS é uma agência internacional de saúde que atua na construção de recomendações e padrões de saúde para os países signatários, formada por especialistas em saúde de diferentes lugares do globo. Desde 1948, quando foi criada, ganhou protagonismo no direcionamento das concepções e ações de saúde adotadas mundialmente. 
a oms define a violência como:

[...] uso intencional da força física ou do poder, real ou em ameaça, contra si próprio, contra outra pessoa, ou contra um grupo ou comunidade que possa resultar ou tenha alta probabilidade de resultar em morte, lesão, dano psicológico, problemas de desenvolvimento ou privação (KRUG, 2002, p. 5).

Essa definição associa intencionalidade à prática do ato propriamente dito, independentemente do resultado. A avaliação da intenção não ocorre no campo moral, mas a depender do contexto é considerada como uma intenção desenvolvida por múltiplas causas, que podem ser evitadas por ações públicas. A intencionalidade também diferencia os resultados de ações violentas de resultados acidentais. Fatos não intencionais, como acidentes de trânsito e queimaduras acidentais, não são, portanto, incluídos no conceito. Além disso, a definição da oms comporta uma conceituação de violência que incorpora relações mais amplas e estruturais baseadas em ações de poder, que contemplam outras formas de violência como negligências, omissões, privações e abusos. Considerando os objetivos propostos pela Carta de Alma Ata ${ }^{3}$ e demais documentos internacionais, a intervenção da violência no campo da saúde deve ir além do aspecto curativo e incluir a prevenção e promoção da saúde:

O setor saúde desempenha um papel fundamental, não só na atenção e reabilitação das vítimas, mas também na implantação de projetos de prevenção, desenvolvimento de sistemas de informação e impulso à pesquisa nas causas e fatores de risco (opas/oms, 2003, p. 1).

3. 0 documento chamado Carta ou Declaração de Alma-Ata resultou da Conferência Internacional sobre Cuidados Primários de Saúde, realizada em 1978 pela OMS. O documento estabeleceu dez prioridades para a efetivação dos cuidados primários em saúde, em âmbito mundial. Ganhou notoriedade e se tornou um marco por estabelecer um conceito de saúde ampliado, bem como por dar centralidade à atenção primária. 
A Resolução CD 44/154 (opAs/oms, 2003) apresenta alguns argumentos que afirmam a necessidade de trabalhar a violência no contexto da saúde: 1 ) a violência, seja interpessoal ou coletiva, produz altas taxas de mortalidade e morbidez, de modo particular em crianças, mulheres e jovens; 2) exige muitos recursos no atendimento e assistência às vítimas de violência; 3) gera impactos não só na vítima, mas também na sua família e no ambiente, nos aspectos econômicos, sociais e psicológicos, a médio e longo prazos; 4) atinge também o responsável pelo ato de violência, sua família e sociedade, e gera diversas despesas; 5) afeta de modo negativo o desenvolvimento social e econômico das comunidades e países; 6) atinge de diferentes formas a vida cotidiana, a liberdade de locomoção e o direito a usufruir bens públicos.

A saúde pode contribuir para que a violência seja evitada e o seu impacto minimizado, de acordo com o "Relatório mundial sobre violência e saúde" (KRUG, 2002). Trata-se de um importante marco no debate ao substituir a categoria "causas externas" da Classificação Internacional das Doenças, que inclui acidentes e violências, pela expressão "violência e saúde". Além disso, nesse documento, a violência é debatida no contexto da violência juvenil, abuso infantil e negligência, violência por parceiros íntimos, abuso de idosos, violência sexual, auto-infligida e coletiva.

No contexto brasileiro, o documento "Violência: uma epidemia silenciosa” ${ }^{\circ}$ observa que a violência encontra-se cada vez mais difusa na sociedade, se configurando como epidemia (BRASIL, 2007). Não se trata de um fenômeno

4. A Resolução 15 do $44^{\circ}$ Conselho Diretor sistematiza a concepção e análise das agências OPAS/ MS sobre a repercussão da violência na saúde das populações americanas, com a apresentação da situação social e das ações propostas aos Estados membros como forma de combate a esse contexto. É construída como base para a criação do Segundo Plano de Prevenção Regional da Violência a partir de 2003, tendo em vista que o primeiro plano é referente a 1994.

5. $O$ documento é produto de uma iniciativa do Conselho Nacional de Secretários de Saúde (CONASS), com o objetivo de incluir o tema violência na agenda de prioridades do SUS. Para tanto, o Conselho promoveu cinco seminários regionais e um nacional para a discussão do tema com representantes estaduais e municipais, entre governo e sociedade civil, o que desembocou na construção de um documento síntese e norteador no ano de 2007. 
natural, mas resultante do desequilíbrio de relações sociais, econômicas e políticas. Diversos estudos mostram o aumento da violência no país nas últimas décadas, especialmente a partir da década de 1980, principalmente a partir das taxas de mortalidade e morbidade da população. De acordo com o Atlas da Violência 2019, em 2017 houve 65.602 homicídios no Brasil, o maior nível histórico de letalidade violenta intencional no país. Há ainda uma concentração em determinadas áreas geográficas, com destaque para o crescimento da taxa de homicídios nas regiões Norte e Nordeste, influenciado pelo narcotráfico, e em alguns grupo sociais, principalmente negros, população LGBTI e mulheres (IPEA, FBSP, 2019).

Embora os serviços de saúde não atuem diretamente sobre as causas objetivas da violência, neles são desenvolvidos atendimentos relacionados a essa temática. Minayo (2006b) apresenta que a violência afeta a saúde de diferentes modos, uma vez que pode provocar mortes, lesões, traumas e diversos agravos; reduzir a qualidade de vida das pessoas e coletividade; exigir readequação da organização dos serviços de saúde; colocar novos problemas para os atendimentos médicos; e evidenciar necessidade de atuação interdisciplinar, multiprofissional e intersetorial.

Pesquisas também mostram os elevados custos da violência para o sistema público de saúde. O estudo "Análise dos custos e consequências da violência no Brasil" analisou os gastos com violência nos sistema públicos de segurança pública, prisional e de saúde e afirmou que, segundo estimativas, em 2004, o custo da violência no Brasil foi de 92,2 bilhões, o que representou 5,09\% do Produto Interno Bruto e um valor de $\mathrm{R} \$ 519,40$ per capita. No contexto da saúde, os custos para tratamento de vítimas de causa externa, de agressões e de acidentes de transporte corresponderam, respectivamente, a $\mathrm{R} \$ 3,8$ bilhões, $\mathrm{R} \$ 206$ milhões e $\mathrm{R} \$ 769$ milhões (cERQUEIRA et al., 2007). Desta forma, a violência como problema de saúde pública demanda planejamento social que destine recursos econômicos e humanos específicos, criação de serviços especiais, capacitação dos profissionais, pesquisas que busquem compreender as causas e possíveis enfrentamentos do problema, campanhas educativas, além de influir sobre o fluxo de atendimento. 
Outro marco no debate sobre violência na saúde é a "Política Nacional de Redução da Morbimortalidade por Acidentes e Violência”' (BRAsil, 2002), que coloca o tema como problema social e histórico e situa os paradigmas da promoção da saúde e da qualidade de vida. Diferenciando violência e acidente, a política aborda de modo particular as fontes de informação e documentação oficial existentes. Embora não sejam abordadas manifestações da violência em situações específicas, o documento abre espaço para esse debate e orienta a discussão a partir dos seguintes princípios: 1. saúde como direito fundamental e requisito para o desenvolvimento social e econômico; 2 . direito ao respeito à vida como valor ético central; 3. promoção da saúde como fundamento de qualquer ação para redução das violências e acidentes.

A literatura também aponta que o tema violência vem sendo tradicionalmente problematizado em contextos específicos, a partir de critérios como sexo e idade. A violência contra crianças e adolescentes, por exemplo, foi inicialmente debatida no contexto brasileiro por profissionais de saúde, que denunciaram agressões, negligências e abusos, e organizações não governamentais, que apresentaram propostas aos marcos tradicionais de debate sobre o tema (MINAYo, 2006B).

A partir dos anos 1990 houve um aumento da produção científica sobre violência no contexto da saúde. Em pesquisa sobre a produção bibliográfica a respeito da violência publicada do início do século xx até o fim dos anos 1980, Souza et al. (2003) registram que $86 \%$ da produção acadêmica foi dos anos 1980 e que os principais temas de interesse eram violência, acidentes e mortes no trabalho; tentativas, ideações e mortes por suicídio; violência e maus-tratos contra crianças, adolescentes e outros grupos específicos; e mortalidade em geral. Já as publicações da década de 1990 se concentraram mais nos temas violências e acidentes; violência contra crianças e adolescentes; acidentes e

6. A Política mencionada é regulamentada na forma da Portaria n 737/2001, pelo Ministério de Saúde, após proposta da Comissão Intergestores Tripartite (CIT) e do Conselho Nacional de Saúde. Isto é, se deu após iniciativa de diversos setores do governo que atuam na área da política de saúde e de representantes da sociedade civil. A Política atua como instrumento normativo que norteia a política de saúde sobre o tema. 
violência no trabalho; prevenção; e violência relacionada a álcool e drogas (souza et al., 2003).

Schraiber, D'oliveira e Couto (2006) realizaram uma pesquisa sobre a produção científica publicada na base de dados Scientific Eletronic Library Online (scielo) e levantaram 234 artigos que tratam do tema violência publicados entre 1980 e 2005 . Os pesquisadores constataram que os estudos nacionais seguiram a agenda internacional de pesquisa, em que inicialmente os temas eram orientados pelos dados de mortalidade por causas externas e, a partir da década de 1990, foram baseados na premissa de que a violência vem crescendo. Ainda nos anos 1990, as pesquisas realizadas tiveram diferentes enfoques, como o entendimento da magnitude e importância da violência como causa de mortalidade em relação a taxas e anos de vida potencialmente perdidos a partir de causas, sexos e idade, e a violência como resultado da metropolização, deterioração urbana e desigualdades nas condições de vida. O maior crescimento das publicações foi nos anos 2000, quando também ocorreu maior visibilidade dos estudos sobre violência no contexto da saúde (SCHRAIBER, D'OLIVEIRA, COUTO, 2006).

Com base nos diferentes estudos apontados, pode-se afirmar que a produção científica sobre violência resultou de mudanças da realidade, que registrou o crescimento dos índices de violência no país a partir da década de 1990. Assim como ganhou maior relevância no âmbito da sociedade acadêmica, passando a influenciar a conformação do tema na agenda pública, tal como a política de saúde.

Diante do exposto, o objetivo neste artigo é analisar como as diversas expressões da violência têm sido historicamente debatidas e apresentadas nos relatórios das Conferências Nacionais de Saúde (CNs) a partir do ano 2000. A Conferência, como espaço público de deliberação que determina as diretrizes da política pública de saúde e reúne diferentes atores sociais, se torna um espaço privilegiado de participação e de compreensão do movimento sócio-histórico da sociedade civil e do Estado brasileiro para a definição da violência como problema de saúde pública. 


\section{Metodologia}

Com metodologia qualitativa, o presente estudo utiliza da técnica de pesquisa documental. Laville e Dionne (1999, p. 166) definem documento como “toda fonte de informações já existente”. Entende-se que os documentos aqui analisados são resultados de um processo social complexo, dinâmico e contraditório, qual seja as Conferências Nacionais de Saúde - cNs, que se configuram como espaços públicos de planejamento e avaliação da saúde pública no Brasil realizadas a cada quatro anos. Nelas são debatidas as diretrizes e prioridades dessa política para o Governo Federal.

As cNs se configuram como espaços públicos de decisão compartilhada com ampla participação de gestores, profissionais, instituições da sociedade civil e usuários de serviços de saúde de todo o país. Ao final de cada uma delas, a comissão organizadora é responsável pela construção de um documento síntese no qual são apresentadas as deliberações aprovadas, as moções e notas registradas como resultado das discussões políticas entre os participantes. O documento geralmente é apresentado em forma de relatório final. Por isso, estes documentos foram elencados como referência da análise documental das CNs.

Os relatórios finais da XI, XII, XIII, XIV, XV e XVI CNS, realizadas respectivamente em 2000, 2003, 2007, 2012, 2015 e 2019, foram recuperados pelo site http://conselho.saude.gov.br/, compreendendo o período de análise do presente estudo, qual seja 2000 a 2019. A justificativa metodológica para a análise dessas conferências é o recente debate sobre o tema violência, que embora iniciado nos anos 1990, ganhou maior consolidação nos anos 2000, quando se avança na adoção das orientações normativas à luz de diretrizes internacionais e os aumentos do índice de violência no país passam a influenciar pesquisas e políticas nacionais na construção de medidas interventivas, particularmente na saúde.

Para a sistematização dos dados, foi elaborado um formulário que buscou identificar "informações gerais da CNs": tema, data, número de participantes e eixos temáticos; e "informações específicas em torno do tema violência”: conceito, propostas intersetoriais e públicos específicos. A busca das informações 
específicas ocorreu a partir de uma lista de palavras-chaves correlatas escolhidas a partir da classificação dos tipos de violência segundo a oms: agressão, homicídio, suicídio, maus-tratos, abuso sexual, abuso psicológico, negligência, abandono, exploração sexual. A elaboração do instrumento de coleta de dados e sistematização das informações contribuiu para a análise uniforme e completa dos relatórios, conforme a análise de conteúdo de Bardin (2009).

\section{As Conferências Nacionais de Saúde}

A Constituição Federal de 1988 legitimou o direito de participação da sociedade civil na gestão das políticas públicas como resultado do processo de democratização. Nesse período, a participação foi reivindicada como direito político e coletivo para a gestão do público, com o objetivo de "mudar as regras do controle social e de alterar a forma de fazer política no país" (GOHN, 2011, p. 53). Com efeito, a participação social se tornou uma das diretrizes do Sistema Único de Saúde (sus) brasileiro, regulamentado pela Lei no 8.142/1990, que estabelece a Conferência de Saúde e o Conselho de Saúde como instâncias colegiadas de controle social ${ }^{7}$. É interessante observar que esta foi uma complementação ${ }^{8}$ à Lei Orgânica do sus,

7. Conforme a lei mencionada, o Conselho é um órgão colegiado, permanente e deliberativo que conta com a participação de representantes governamentais, prestadores de serviços, profissionais de saúde e usuários do SUS na formulação e controle da execução da política de saúde. A Conferência, por sua vez, se reúne a cada quatro anos para avaliar a política de saúde e estabelecer diretrizes à agenda pública.

8. A Lei Orgânica do SUS, é instituída num cenário de democratização associado à emergência do neoliberalismo, formado pelo gerencialismo empresarial no modo de se pensar e fazer políticas públicas. Desse modo, a abrangência e conformação do SUS presenciou um cenário de disputas políticas antes e depois da sua implantação protagonizada por diferentes atores políticos. Quando publicada, sofreu vetos por parte do presidente da República como forma de conter a proposta ampliada de política pública. Mesmo com os vetos sofridos, a lei ampliou e tornou a Política abrangente. No mesmo ano, como resultado do movimento sanitarista e de demandas populares, a lei complementar 8142/1990 regulamentou as instituições colegiadas de participação social da política de saúde vetadas anteriormente. 
Lei no 8.080/1990, após o veto do então presidente Fernando Collor de Melo à parte que tratava da participação social (RICARDI et al., 2017).

As conferências, enquanto fenômeno político, possuem uma qualidade específica na gestão das políticas públicas por possibilitarem a interação entre Estado e sociedade na formação da agenda política, isto é, no direcionamento da política pública, elencando prioridades, objetivos e diretrizes de acordo com os sujeitos políticos que participam ativamente seja nas esferas municipais, estaduais/distrital ou nacional (souza et al., 2013). As Conferências são espaços privilegiados de gestão da política de saúde ao possibilitar uma reforma orientada pela democratização das decisões políticas com a participação ampliada nos processos de análise da situação, definição de prioridades e formulação da política pública (TOFANI, CARPINTÉRo, 2012).

De acordo com a Lei no 8.142/1990, as Conferências se reúnem a cada quatro anos para avaliar a situação de saúde do país e propor as diretrizes para a formulação dessa política. Elas são convocadas pelo Poder Executivo, ou extraordinariamente, por outra Conferência ou pelo Conselho de Saúde. Destaca-se que as cNs são resultado de um processo iniciado em etapas locais. Assim, as discussões da Conferência Nacional tem como base os debates ocorridos anteriormente nos municípios e estados por delegados que, posteriormente, levam as demandas coletivas de cada região para a fase nacional. As deliberações da Conferência são apresentadas no Relatório Final no formato de diretrizes, propostas e moções, de modo a subsidiar a gestão e possibilitar o monitoramento por parte da população além de formar a agenda política de saúde para os próximos quatro anos (GUIZARD et al., 2004).

As CNS são, portanto, um instrumento de planejamento público democrático que, embora tenham sido redimensionadas neste período, são anteriores à promulgação do sus e da Constituição. A primeira foi criada em 1937 e ocorreu em 1941 ainda no governo Vargas, caracterizada por seu caráter técnico e burocrático, além da limitada participação da sociedade (souza et al., 2013). Segundo Sayd et al. (1998), as duas primeiras cNs, 1941 e 1961, foram marcadas pelo sanitarismo clássico com uma proposta orientadora para a organização geral da saúde brasileira. Na Conferência de 1963, por sua vez, é possível 
identificar a polarização política e ideológica do período com projetos políticos em disputa e maior abertura à participação. Todavia, o período ditatorial registrado pelo centralismo autoritário influenciou a dinâmica das CNs dos anos de 1967, 1975, 1977 e 1980. As duas primeiras do período ganharam maior incidência do planejamento estatal, de caráter rígido e técnico; as duas últimas também carregam marcas do período, mas se caracterizam pela distensão do regime ditatorial e fragilidade das políticas de saúde e previdência na época (sAYd et al., 1998).

Apenas em 1986, com a realização da viı Conferência, a cNs passou a ser um espaço ampliado de participação de diversos segmentos, com maior incidência da sociedade civil. Trata-se de um marco na trajetória da política de saúde na medida em que a discussão social sobre um sistema único ganha corpo e a participação é entendida como promotora da construção coletiva do direito à saúde, que possibilita o controle social da população no processo de planejamento e avaliação da política (GUiZARDi et al., 2004). Essa Conferência socializou e politizou o debate sobre saúde, além de ter incorporado as diretrizes da reforma sanitária. Correspondente à conjuntura de abertura democrática, o espaço conseguiu ampliar as bases políticas enquanto esfera pública.

Posteriormente, as conferências referentes aos anos de 1992 e 1996 deram sequência às iniciativas pautadas em 1986 e ao aprofundamento do que foi estabelecido na Lei 8080/1990. Isto é, as prerrogativas básicas dessas conferências estavam ancoradas na implementação do sus, o que estabeleceu a ampliação das deliberações sobre concepção de saúde, gestão, financiamento, descentralização e controle social. O cenário da década de 1990, em contraposição, era permeado por disputas ideológicas no âmago da consolidação neoliberal, voltada para a retração dos direitos sociais e privatização do público. Desse modo, é perceptível nos relatórios finais destas conferências a defesa do público em detrimento do privado e o esforço em tentar garantir a implementação do sus a nível nacional.

A X Conferência, em 1996, avançou ainda sobre a demarcação de assuntos específicos como a necessidade de políticas específicas na saúde para mulheres, pessoas idosas, pessoas com deficiência, entre outros, apresentando apenas a 
indicação do estabelecimento temático. Assim, a violência ainda não aparecia como questão de planejamento, prevenção e intervenção da política de saúde. Apenas nos anos 2000 esse debate começa a florescer nas conferências nacionais, associando-se ao aprofundamento do tema nas normativas internacionais, à ampliação das publicações de pesquisas sobre essa questão e ao aumento dos índices de violência no país.

Embora seja reconhecido o avanço democrático das conferências, Ricardi, Shimizu e Santos (2017), ao analisarem os relatórios finais das XII, XIII, XIV e XV CNs, identificam limites na efetividade deste espaço devido à falta de continuidade, reflexão sobre a própria gestão do sistema e a falta de monitoramento e avaliação das ações. Os limites democráticos são estruturais nas políticas sociais brasileiras, mas a disputa e tensionamento continuam tendo expressão e validade nos canais de participação que configuram o controle social. É nesse sentido que o intuito desse artigo não está apoiado na análise da implementação das deliberações presentes nos relatórios das CNS, mas em elencar como os sujeitos políticos que disputam a saúde pública brasileira apresentam a violência e as suas expressões nesse espaço democrático conformando a concepção de violência na agenda pública.

\section{Conferência Nacional de Saúde: o Brasil falando como quer ser tratado}

Ocorrida em dezembro de 2000, a xi Conferência Nacional de Saúde, com o tema "Efetivando o sus: acesso, qualidade e humanização na atenção à saúde com controle social”, contou com a presença de 2.500 delegados e deu destaque aos temas participação e controle social. Contextualizando a realidade nacional, o relatório cita aspectos como desemprego, desigualdades na distribuição de renda, fome e desnutrição, falta de qualidade de vida e de saúde da população, pagamento da dívida pública e ajuste fiscal. A principal proposta defendida foi, então:

[...] a melhoria das condições de saúde e da existência efetiva de políticas sociais intersetoriais e de um compromisso irrestrito com a vida e a 
dignidade humana, capaz de reverter os atuais indicadores de saúde, contribuindo assim para a melhoria da qualidade de vida da população (BRASIL, 2001, p. 14).

O ano de 2000 presenciou o último governo do presidente Fernando Henrique Cardoso, adepto e promotor da neoliberalização da esfera pública. No momento, as políticas sociais eram direcionadas sobre a égide do ajuste fiscal e trinômio neoliberal: privatização, focalização e descentralização do público para o privado (DRAIBE, 1993). O ano de 1999 acabava de registrar um aumento exponencial da extrema pobreza, desemprego e baixa execução orçamentária de programas sociais e investimentos do governo federal no país (BEHRING, 2003). Diante dos ataques à universalização da saúde pública, com incentivo aos convênios e planos privados em detrimento da politização dos seus princípios originais, a CNS registrou os embates políticos e econômicos do momento, com destaque para os movimentos sociais consolidados na área que conseguiram fazer com que as diretrizes do público, universal e equânime fossem prevalecentes nas deliberações finais.

A Conferência afirma que a saúde é influenciada por diversos determinantes sociais, dentre eles, está a violência. Uma das propostas do eixo "Determinantes das condições de saúde e problemas prioritários no país" defende a prerrogativa de "Considerar a violência um problema de Saúde Pública e enfrentá-la com um corpo articulado de políticas saudáveis, que se contraponham a partir de vários pontos e com estratégias diversificadas, às determinações e efeitos da violência” (BRAsıl, 2001, p. 109). Embora se reconheça a violência enquanto problema de saúde, esse tema é pouco aprofundado, sendo citado apenas em outros três contextos: violência contra mulher, violência no contexto da saúde mental, e violência e polícia. Nesse sentido, o relatório apresenta uma lacuna em relação ao debate da violência contra criança e adolescente, contra idoso e outros grupos vulneráveis.

A Conferência reconhece a ausência de serviços de saúde para a abordagem da violência doméstica e sexual contra a mulher, estando integradas propostas voltadas à assistência integral à saúde da mulher. Uma das propostas, 
no eixo "Saúde da Mulher”, afirma:

A expansão e interiorização do processo de implantação dos serviços de atendimento às mulheres vítimas de violência sexual, garantindo a implementação da "Norma Técnica de Prevenção e Tratamento dos Agravos Resultantes da Violência Sexual Contra as Mulheres e Adolescentes na Rede Pública de Saúde”, incluindo a prevenção das DsT/Hiv/AIDs, contracepção de emergência e a realização do aborto conforme determinações do Código Penal. Instituição de políticas que propiciem às mulheres vítimas de violência doméstica e sexual romper com o ciclo de violência. Inclui-se aqui a criação de condições para o estabelecimento de uma rede de proteção a essas mulheres, e a criação de Casas Abrigos com atendimento multidisciplinar (BRASIL, 2001, p. 135/136).

Sugere-se uma atuação intersetorial a partir da criação de uma rede de proteção a essas mulheres, que envolverá necessariamente diferentes políticas sociais e uma atuação multidisciplinar, uma vez que a violência contra a mulher apresenta impacto para diferentes aspectos da vida, contemplando o conceito ampliado de saúde. Outra proposta da Conferência é a divulgação da norma técnica de serviços de atendimento às mulheres vítimas de violência sexual.

O eixo "Saúde Mental" reconhece "a possibilidade de se fazer Psiquiatria sem necessidade de violência, da exclusão e da negação" (BRASIL, 2001, p. 138), o que sugere ações humanizadas no atendimento desse público, como fim dos manicômios e fiscalização dos hospitais psiquiátricos; busca do direito e da cidadania; reabilitação psicossocial; participação ativa dos familiares e responsáveis no tratamento; busca pela desinstitucionalização e autonomia. A proposta é, portanto, acabar com um tipo de violência existente dentro do próprio sistema de saúde contra os usuários de serviços de saúde mental. Por fim, a articulação entre violência e Polícia visa à organização de um Sistema de Vigilância das Violências, o qual foi aprimorado e expandido para outras instituições na XII Conferência. 


\section{Conferência Nacional de Saúde: Conferência Sérgio Arouca}

A xir Conferência Nacional de Saúde, com o tema "Saúde um direito de todos e um dever do Estado. A saúde que temos, o sus que queremos.", aconteceu em dezembro de 2003 e reuniu cerca de 4.000 delegados, 1.500 a mais do que no evento anterior, o que pode demonstrar a expansão do espaço de decisão da política de saúde. Contextualizado pela posse do Presidente Lula em janeiro de 2003, o relatório afirma um novo momento histórico para o país, que buscou revisar os 15 anos do Sistema Único de Saúde e seus desafios, apontando para remediar as consequências deletérias dos últimos anos e da ampliação do caráter público e de qualidade na política de saúde. No que tange à temática da violência, percebe-se um debate mais elaborado, relacionando o tema a políticas intersetoriais e, ao mesmo tempo, voltado a grupos específicos.

No eixo "A intersetorialidade das ações de saúde", a violência, juntamente com desemprego, êxodo rural, fome, insegurança alimentar, habitação insalubre e contaminação ambiental, se situou como contexto de risco à saúde, demandando atenção na formulação de políticas. Além disso, a violência, assim como na Conferência anterior, passou a ser tratada como problema de saúde pública, conforme a seguinte proposta: "Considerar a violência, em todas as suas modalidades, como expressão das iniquidades sociais e assunto prioritário de saúde pública, desenvolvendo políticas intersetoriais para seu enfrentamento" (BRASIL, 2004, p. 47).

Para tanto, foram sugeridas ações que integrem educação, saúde, segurança pública, segurança alimentar, assistência social, comunicação, direitos humanos, cidadania, uso de drogas lícitas e ilícitas e comprometimento dos profissionais de saúde. Merece destaque a ação de criar centros de estudos de violência, com caráter interdisciplinar e multidisciplinar, com o objetivo de auxiliar a formulação de políticas públicas. Outra proposta sugere viabilizar pesquisas com recursos do Ministério da Saúde, e dentre os temas, se encontra a organização de sistema de vigilância à violência que viabilize a obtenção de informações de morbimortalidade por causas externas e vigilância epidemiológica dos óbitos.

Também se propõe "formar uma rede de âmbito nacional para a cultura 
da paz, coordenada pelas diversas instituições governamentais e não-governamentais para reduzir os índices de violência” (BRAsıL, 2004, p. 48), e estabelecer ações intersetoriais que visem à promoção da igualdade racial e de gênero, com o objetivo de combater preconceitos, discriminações e violências. Sugere-se articular ações intersetoriais com a Polícia Militar nas áreas com elevados índices de violência, com o objetivo de minimizar situações de risco para profissionais de saúde e usuários.

A violência contra mulher é apresentada diversas vezes no relatório, de modo particular no contexto da "Ação Integral à Saúde da Mulher", sendo garantidos direitos sexuais e reprodutivos. Busca-se "garantir acesso ao atendimento integral às pessoas vítimas de violência sexual, incluindo o acolhimento no protocolo de atendimento, o respeito à integridade física, moral e psíquica das pessoas e a humanização do pronto atendimento, utilizando todo o sistema de saúde, com abordagem multiprofissional e intersetorial" (BRAsIL, 2004, p. 88), o que significa ampliar o atendimento e contemplar outros elementos. Além disso, é proposto o transporte para as mulheres em tratamento continuado, inclusive, vítimas de violência, de modo a evitar o abandono ao tratamento, e a criação e implantação de novas casa-abrigo, estando entre um dos compromissos da saúde identificar as vulnerabilidades à violência.

A saúde mental também foi reafirmada enquanto espaço de implementação de políticas de saúde que primam pela qualidade, pela cidadania e pela participação da população. Porém, a proposta relativa à violência na saúde mental não se apresenta de forma clara e objetiva, o que dificulta a compreensão de seu real sentido: "solicitando que os Caps atendam aos familiares de pessoas vítimas de violência, visando a criar argumentos contra os que atacam os Direitos Humanos dizendo que eles cuidam do bandido, mas não atendem aos familiares das vítimas." (BRASIL, 2004, p. 92). Além disso, a violência foi contextualizada na reabilitação de dependentes químicos de modo a ser efetivada a promoção da saúde e da cidadania e a redução da violência. Os debates sobre o tema também foram incorporados no contexto da violência contra crianças e adolescentes, enquanto situação de vulnerabilidade, sendo necessário efetivar uma política de prevenção à violência, contra exclusão e discriminação, com 
aplicação de protocolos de atendimento interdisciplinar e com a notificação compulsória no sus, sendo encaminhado para os serviços de apoio, proteção e tratamento adequados. Na política de educação, acidentes e violências também são incorporados como eixo de promoção da saúde.

Outras inovações dessa Conferência foram o tratamento particular dado a saúde do homem, enquanto área que necessita de políticas específicas, inclusive, para violência; e a atenção à violência dentro das próprias condições de trabalho na saúde, como afirma essa proposta: "criar cartilha dirigida ao servidor público, independentemente de seu vínculo de trabalho, esclarecendo seus direitos e deveres, destacando informações dirigidas a trabalhadores e usuários para estimular o respeito mútuo e a redução da violência nas relações de trabalho" (BRAsıl, 2004, p. 121). Também são propostas ações para educação permanente dos trabalhadores da saúde de modo a qualificá-las na abordagem intersetorial da violência, assédio sexual e assédio moral, assim como ações de humanização no atendimento. Por fim, merece destaque a proposta de criar ações que visem diminuir violência e acidentes no trânsito e no trabalho. Percebe-se um trato mais especializado sobre a violência em relação à conferência anterior, com maior atenção às determinações e efeitos específicos da violência, além de reconhecer que todos eles são competência da política de saúde.

\section{Conferência Nacional de Saúde: Saúde e Qualidade de vida: políticas de estado e desenvolvimento}

A xiı Conferência Nacional de Saúde, que aconteceu em novembro de 2007, contou com quase 5.000 participantes, entre gestores, trabalhadores, usuários, parlamentares e professores e debateu diversos temas, como intersetorialidade, modelo de atenção à saúde, financiamento do sus, recursos humanos e trabalho no sus. Embora o otimismo e a credibilidade política não fossem mais tão presente como no início do governo Lula, devido aos escândalos de corrupção como o Mensalão, o cenário econômico gozava de um mínimo de estabilidade e as conferências de saúde estavam alcançando um aprofundamento democrático decorrente da continuidade dos debates promovidos desde 1986. 
Em relação ao tema violência, percebeu-se significativos avanços no debate. Primeiramente, se observa uma ampliação da compreensão do tema violência, que passou a incorporar diferentes formas de manifestação na sociedade, e do espaço de atuação da saúde com a temática violência. No eixo "Desafios para a efetivação do direito humano à saúde no Século xxı: Estado, sociedade e padrões de desenvolvimento", foi encontrada a seguinte proposta: "Defender a democracia, a paz e a tolerância, em suas variadas formas, além de maior igualdade na distribuição de renda, como condição essencial para a redução de conflitos entre povos, e a exacerbação da violência social" (BRAsiL, 2008, p. 20).

Nesse mesmo sentido, se propõe a implantação de uma rede pública de protocolos de atenção contra todos os tipos de violência e atendimento integral às vítimas de qualquer tipo de violência. A questão da intersetorialidade perpassa diversas propostas, como a articulação com Conselhos Tutelares, Ministérios Públicos, Segurança Pública e outras instituições no acompanhamento e acolhimento dos casos de maus-tratos e violência à pessoa com transtornos mentais; e a articulação com políticas de segurança, assistência social e saúde, para o atendimento de mulheres vítimas de violência.

A Conferência também propõe ações de prevenção à violência como a criação de programas de educação permanente em saúde, além de:

implementar serviços de atendimento interdisciplinar (com referência e contra-referência), notificação compulsória, ações educativas, grupos socioeducativos e campanhas contra as violências/causas externas que envolvam crianças e adolescentes, bem como garantir, na rede de saúde existente, a prevenção, a promoção e a assistência multiprofissional ao adolescente que comete violência e abuso sexual (BRAsıL, 2008, p. 107).

A violência contra a mulher passou a ser orientada, nessa Conferência, a partir da Lei Maria da Penha ${ }^{9}$, e foi novamente proposta a implantação

9. A Lei 11.340 de 2006 institui mecanismos de enfrentamento à violência doméstica e familiar contra a mulher. A normativa ficou conhecida por Maria da Penha, em sua homenagem e por ter 
de casas de acolhimento para mulheres vítimas de violência. Além disso, foi inserida a proposta da "obrigatoriedade de notificações de casos de violência contra a mulher em todos os serviços de saúde e órgãos públicos” (BRAsIL, 2008, 47). Essa medida já havia sido instituída pela Lei no $10.778 / 2003$, que afirmava ser objeto de notificação compulsória, em todo território nacional, a violência contra mulher atendida em serviços de saúde públicos e privados. Por ser objeto de debate nessa cNs, considera-se que sua implementação estava fragilizada. A violência contra crianças e adolescentes, por sua vez, continua a ser vista no contexto do Programa de Atenção Integral à Saúde da Criança e do Adolescente, juntamente com outras situações de vulnerabilidade e risco à saúde, como gravidez na adolescência, dependência química, DsT/Aids.

Nessa Conferência, do mesmo modo que na anterior, é proposta a realização de pesquisas e estudos sobre os impactos da violência no perfil de morbimortalidade e dimensionamento das sequelas provocadas por agressões intrafamiliares, violências no trânsito e no trabalho, de modo a contribuir para a realização de atividades educativas e oferta de ações e serviços que atendam a essas demandas. Para tanto é proposta a implementação da "Política Nacional de Redução da Morbimortalidade por Acidentes e Violências” em diversos contextos.

O relatório cita, em diversos momentos, a busca por romper com práticas que discriminam e excluem determinados grupos sociais, como o exemplo do seguinte trecho: "Elaborar políticas públicas intersetoriais e transversais voltadas às pessoas em situação de rua, portadoras ou não de transtornos mentais, usuários de drogas e com necessidades especiais, repudiando práticas higienistas, repressivas e a violência que incide sobre esses segmentos populacionais" (BRASIL, 2008, p. 40). Percebe-se que essa proposta afirma princípios

sido resultado da luta judicial que ela combateu para conseguir penalizar o marido que cometeu inúmeras violências em decorrência do seu gênero, deixando-a com sequelas físicas e psicológicas. A disputa com o seu até então marido e a negligência judicial ocorreu por quase vinte anos, até que a Comissão Interamericana de Direitos Humanos interviu no caso, formulando recomendações ao Estado brasileiro. Após disputas entre os poderes públicos e sociedade, a lei foi aprovada em 2006 pelo Senado. 
constitucionais do respeito à dignidade humana e cidadania, e busca efetivar a universalidade da saúde pública, uma vez que abrange grupos vulneráveis e tradicionalmente excluídos e discriminados nos serviços.

O tema violência também é citado enquanto área que merece atenção na política de educação permanente de formação dos profissionais de saúde. Com ênfase na humanização, na promoção da saúde e na integralidade, é buscada a resolutividade em áreas como gênero, violência, dependência química, DST/ Aids, saúde mental, hipertensão/diabetes, autocuidado, cidadania, entre outros. Enfatiza-se, então, a necessidade de formação e qualificação profissional para a atuação nessas áreas, de modo a preparar o sistema de saúde a acolher e atender essas novas necessidades da população.

A violência no trânsito passa a ser reconhecida, oficialmente, como demanda de saúde, conforme a seguinte proposta:

O Ms deve reconhecer a violência no trânsito como grave problema de saúde pública, desenvolvendo atividades educativas, preventivas e punitivas relacionadas ao uso de bicicleta e de equipamentos de proteção aos pedestres definidas por grupo técnico interministerial, garantindo atendimento especializado às vítimas da violência no trânsito, que vitimou 35 mil pedestres, ciclistas e motociclistas e ocasionou uma perda econômica de $30 \%$ do sus em 2006. (BRASIL, 2008, p. 142).

Além disso, se reconhece a necessidade de implementar políticas públicas e atividades intersetoriais na prevenção do suicídio e reconhecer essa questão, enquanto demanda de saúde pública, e particularmente, de saúde mental. $\mathrm{O}$ tráfico de seres humanos, a exploração sexual, a venda de órgãos e o trabalho escravo também passam a ser vistos no contexto da saúde e como formas de violação dos direitos humanos e a da cidadania. Nesta Conferência, percebe-se o trabalho de continuidade em relação à anterior, aprofundando ainda mais o trato especializado sobre a violência, com maior número de deliberações e expressões de violência interrelacionadas com a saúde. 


\section{Conferência Nacional de Saúde: Todos usam o SUS! SUS na Seguridade Social, Política Pública e Patrimônio do Povo Brasileiro}

Em 2012, foi realizada a XIV CNs, com a presença de 2.937 delegados, cerca de 2.000 participantes a menos em relação à passada. As propostas foram distribuídas em 15 diretrizes. Também foi aprovada a Carta da $14^{\text {a }}$ Conferência Nacional de Saúde à sociedade brasileira e diversas moções de apoio, apelo, aplauso, solidariedade e repúdio. A conjuntura política, no período, apresentava sinais de desgastes no governo petista já sob comando de Dilma Rousseff, com embates entre os poderes Legislativo e Executivo e mal estar generalizado em diversos âmbitos da sociedade civil. Como elemento determinante, a economia do país ia de mal a pior, com efeitos perversos à política de saúde.

Logo na primeira diretriz, "Em defesa do sus - pelo direito à saúde e à seguridade social”, identificam-se propostas que tratam as violência no nível estratégico por meio da reativação dos Conselhos de Seguridade Social nas esferas municipal, estadual, distrital e feral, assim como a necessidade de linhas de financiamento pelo Ministério da Saúde para reabilitação de vítimas de acidentes, violências, entre outros.

$\mathrm{Na}$ Diretriz 9, com o debate sobre a ampliação e fortalecimento de políticas sociais, projetos intersetoriais e a consolidação da vigilância e da promoção à saúde, foi identificada a proposta de "Criar, implantar e implementar políticas públicas voltadas à valorização da vida e cultura de paz, nos diferentes ciclos de vida, como mecanismo de prevenção de acidentes (domésticos, no trânsito, no trabalho) e da violência”. Complementar a essa proposta de ação de prevenção, têm-se ações de atendimento a situações de violência. Particularmente na Diretriz 10 está presente o debate sobre violência doméstica, sexual e de gênero, à luz da Política de Atenção à Saúde da Mulher.

A diversidade de públicos vítimas de violência é explicitado em propostas da Diretriz 11, intitulada "Por um sistema que respeite diferenças e necessidades específicas de regiões e populações vulneráveis" do seguinte modo:

14 Implantar redes de atenção e proteção às pessoas em situação de violência 
doméstica e sexual, crianças, adolescentes, adultos, idosos, pessoas com deficiência, transtorno mental e trabalhadores.

20 Incluir a Saúde do Adolescente como um dos eixos prioritários no Pacto da Saúde, garantindo o acesso aos serviços integrais da Rede de Atenção na Promoção, Proteção e Recuperação relacionadas ao: Planejamento Familiar, Gravidez na Adolescência, DsT-Aids, Hepatites Virais, Violências, uso de álcool, cigarro, crack e outras drogas, estimulando hábitos alimentares saudáveis e a prática regular de atividade física, entre outros.

No que se refere às moções, destaca-se a Moção de Repúdio no 11 destinada ao Governo Federal, que trata da situação das terras indígenas e da vulnerabilidade social e constantes conflitos com povos indígenas, que geram altos índices de violências, homicídios, suicídios, desnutrição e degradações sociais. Destaca-se que esse público não havia sido mencionado como vítima de violência em Conferências anteriores. Embora a moção tenha sido registrada, não se transfigurou em deliberação. De modo geral, pode-se afirmar que a Conferência de 2012 possuiu um caráter reduzido comparada às anteriores, com menos participantes e com enxugamento no número de deliberações.

\section{Conferência Nacional de Saúde: Saúde pública de qualidade para cuidar bem das pessoas: direito do povo brasileiro}

A xv cNs ocorreu no ano de 2015, com o tema "Saúde pública de qualidade para cuidar bem das pessoas: direito do povo brasileiro". Um ano antes do impeachment de Dilma Rousseff, o período já registrava instabilidade desde as manifestações de junho de 2013, que marcaram o processo de crise de representatividade do governo e o ódio conservador ao Partido dos Trabalhadores. A falta de impulso às medidas econômicas de saída da crise norteadas pelo bloco no poder também foi um elemento decisivo. Nos termos de Silva e Lima (2019, p. 110), "A partir da crise econômica e da crise política que marcaram a história do Brasil, especialmente a partir de 2014, e culminaram com o impeachment da presidente Dilma, em 2016, a conjuntura política passou a ser uma 
questão central na etapa nacional da $15^{\mathrm{a}} \mathrm{CNs} . ”$

Silva e Lima (2019) observam que houve uma preocupação do Conselho Nacional de Saúde em antecipar a realização da cNs para acompanhar o tempo legal de planejamento na esfera federal, tendo em vista que nesse ano seria elaborado o Plano Plurianual e o Plano Nacional de Saúde para o período de 2016 a 2019. Ademais, houve uma mudança metodológica nesse processo com a realização de conferências livres constituídas por plenárias populares nas em todo país, para além das já realizadas conferências municipal, estadual e nacional. A proposta era mobilizar movimentos sociais e entidades, para além das representações institucionalizadas de conselheiros de saúde, e ampliar a representação de grupos minoritários.

O Conselho Nacional de Saúde publicou um documento orientador para os debates da Conferência, em que registra a pertinência da cNs para a democracia e os temas que devem ganhar visibilidade e serem discutidos nos dias das conferências com maior ênfase, além de desenharem propostas de possíveis deliberações. Entre as propostas, três se referem ao debate da violência direcionadas pela defesa do enfrentamento de toda forma de violência, além de registrar o combate a formatos específicos de violência como a violência sexual, de gênero e de raça. São elas:

Combater toda forma de violência, de racismo institucional e social, de discriminação de gênero, diversidade sexual, geracional ou de condição de vida, que venha a comprometer o acesso; [...]

Defender os direitos sexuais e reprodutivos das mulheres sobre sua saúde e sua vida, visando: redução da violência sexual e doméstica, diminuição da mortalidade materna, planejamento reprodutivo, atendimento em situação de aborto, saúde das 9 mulheres jovens/lésbicas/negras/rurais/indígenas/ com deficiências e patologias, e inclusão da abordagem de gênero na formação dos profissionais de saúde (CONSELHO NACIONAL DE SAÚDE, 2015,p. 8)

Reduzir e prevenir riscos e agravos à saúde da população por meio das ações de vigilância, promoção e proteção, com foco na prevenção de doenças 
crônicas não transmissíveis, acidentes e violências, no controle das doenças transmissíveis e na promoção do envelhecimento saudável. (CONSELHO NACIONAL DE SAÚDE, 2015, p. 21)

Silva e Lima (2019) observam mudanças metodológicas nessa Conferência, com limite de propostas a serem enviadas a etapa nacional: cada estado poderia enviar apenas uma diretriz para cada um dos oito eixos e cinco propostas por diretriz. Das 208 diretrizes e 1.040 propostas das conferências estaduais, além da distrital, foram consolidadas no caderno de proposta disponíveis 36 diretrizes e 541 propostas, além de uma diretriz e 35 propostas de Pernambuco que chegaram de forma tardia. Ao final, foram aprovadas na XV cNs 37 diretrizes e 560 propostas.

No entanto, no que se refere aos produtos da conferência, não existe um relatório final tal qual os anteriores. $\mathrm{O}$ documento intitulado "Diretrizes aprovadas nos Grupos de Trabalho ou na Plenária Final - por ordem de votação nos eixos temáticos" registrou as deliberações e é mais enxuto, inclusive sem caracterização da quantidade de delegados participantes do evento. Dividido por oito eixos temáticos, no relatório não há nenhuma diretriz aprovada que contenha os termos elencados no percurso metodológico. Isso significa uma omissão diante dos desafios postos na área, além de um retrocesso democrático e no entendimento de violência como problema de saúde pública. Até mesmo no documento orientador, percebe-se uma redução sobre a apresentação do tema.

\section{Conferência Nacional de Saúde: Saúde e Democracia}

A xvi cNs ocorreu no ano de 2019, com tema saúde e democracia. Tem-se um novo momento político, pós eleição do presidente Jair Bolsonaro, que no mesmo ano publicou o Decreto no 9.759/2019 extinguindo e estabelecendo diretrizes, regras e limitações para colegiados da administração pública federal. Com essa medida, foram extintos conselhos, comitês, comissões e demais espaços participativos, o que gerou tensões quanto à disposição do governo em assegurar o princípio constitucional da participação popular. 
Dividida por um eixo transversal sobre democracia e saúde e três eixos temáticos (saúde como direito, consolidação dos princípios do sus e financiamento adequado e suficiente para o sus), a Conferência deliberou 31 diretrizes e 331 propostas.

Com ênfase no debate democrático, a XVI CNS recupera e reforça várias diretrizes e propostas das conferências anteriores. Em relação à conferência realizada em 2015, ela retoma o tema da violência para às propostas e diretrizes da saúde pública. Avança sobre a concepção de violência, que é apresentada de forma ampla com referência nas estruturas sociais, em que se torna necessário defender a saúde, a democracia e a cidadania para o seu enfrentamento, como apresentado:

Saúde abrange o direito a um sistema político que respeite a livre opinião, a livre possibilidade de organização e autodeterminação de um povo, e que não esteja todo tempo submetido ao medo da violência, daquela violência resultante da miséria, e que resulta no roubo, no ataque. Que não esteja também submetido ao medo da violência de um governo contra o seu próprio povo, para que sejam mantidos interesses que não são do povo (BRASIL, 2020, p. 4).

A Conferência também define na proposta 43 do eixo democracia e saúde que o enfrentamento da violência, como forma de promoção à saúde e cultura da paz, deve ser incorporado nas bases curriculares do ensino básico ao superior, com o apoio do MEc. A XVI CNS ainda defende a atenção pública intersetorial, integral com atuação multiprofissional para o atendimento de pessoas em situação de violência de diversos tipos e grupos específicos, uma vez que a violência gera impactos individuais e coletivos. Ainda na mesma proposta, sugere a criação de equipamentos de abrigo às vítimas de violência. De modo complementar, define como proposta a garantia da equidade no atendimento às pessoas que sofrem violências sociais e institucionais.

No eixo sobre a consolidação dos princípios do sus, a Conferência estabelece a criação de uma rede de atendimento integral às pessoas em situação 
de violência, assim como prazos emergenciais para o atendimento de vítimas de violência sexual. Enfatiza a defesa dos direitos sexuais e reprodutivos das mulheres com o objetivo de reduzir as violências sexual, obstétrica e doméstica. E propõe a prevenção de violências com ações integradas a outras políticas no sentido de promover saúde mental desde a primeira infância.

A Conferência de 2019 significou um marco de resistência dos sujeitos coletivos que disputam a política de saúde. Ainda que mediante às adversidades da conjuntura política, dificuldades para a sua realização e com a repetição de muitas deliberações e diretrizes anteriores, a Conferência registrou qual é o conteúdo da política defendido por diversos setores da sociedade civil brasileira a nível nacional.

\section{Considerações finais}

A inserção da violência com uma concepção mais ampla já é uma realidade no âmbito normativo a nível nacional e internacional. Entretanto, a incorporação do tema como problema de saúde pública necessita de diferentes ações para fazer parte da agenda política do país. Nesse sentido, destaca-se que os debates sobre violência no campo da política pública de saúde partem do conceito ampliado de saúde, que para além de doença, abrange determinantes sociais, econômicos, políticos e culturais.

Desde os anos 2000, a violência ganhou espaço e esteve presente nos debates entre sociedade e Estado nas cNs, possibilitando a construção de um entendimento coletivo e vasto sobre a violência, a forma de monitorá-la e enfrenta-la na saúde. A XI CNs, com abordagem mais abstrata, vaga e com lacunas temáticas. As cNs posteriores avançam tanto na abordagem, como na construção da concepção do tema e das especificidades, como violências de gênero e contra crianças e adolescentes. De modo geral, as Conferências apresentam a violência como problema de saúde, com referência nas estruturas desiguais da sociedade, que conformam determinantes e condicionantes para a ausência de saúde e alteração dos níveis de bem-estar da população. $\mathrm{O}$ quadro abaixo sintetiza as concepções de violência abordadas de acordo com cada conferência: 
Quadro 1: Concepção de violência baseada nas CNS (2000 até 2019)

\begin{tabular}{|c|c|c|c|}
\hline CNS & ANO & NN PROPOSTAS & CONCEPÇÃO DE VIOLÊNCIA \\
\hline $\mathrm{XI}$ & 2000 & 6 & $\begin{array}{l}\text { Considerada como um problema de Saúde Pública. } \\
\text { Seu enfrentamento ocorre com um corpo articulado } \\
\text { de políticas saudáveis, que se contraponham a partir } \\
\text { de vários pontos e com estratégias diversificadas. }\end{array}$ \\
\hline XII & 2003 & 13 & $\begin{array}{l}\text { Entendida por diversas modalidades resultantes das } \\
\text { iniquidades sociais. Deve ser tratada como assunto } \\
\text { prioritário de saúde pública, associada às ações } \\
\text { intersetoriais para seu enfrentamento. }\end{array}$ \\
\hline XIII & 2007 & 20 & $\begin{array}{l}\text { O seu combate é associado à defesa da democracia, da } \\
\text { paz e da tolerância, com a promoção da igualdade na } \\
\text { distribuição de renda. Entendida como resultado das } \\
\text { desigualdades sociais. }\end{array}$ \\
\hline XIV & 2012 & 6 & $\begin{array}{l}\text { Sem concepção definida, é associada à valorização da } \\
\text { vida e da cultura da paz para a sua prevenção. }\end{array}$ \\
\hline $\mathrm{XV}$ & 2015 & 0 & - \\
\hline $\mathrm{XVI}$ & 2019 & 7 & $\begin{array}{l}\text { Sem concepção anunciada, o seu enfrentamento é } \\
\text { associado ao exercício da cidadania, da solidariedade, } \\
\text { da justiça, da participação popular e democrática. Com } \\
\text { referência à Sergio Arouca na afirmação de que "Saúde } \\
\text { abrange o direito [...] que não esteja todo tempo } \\
\text { submetido ao medo da violência, daquela violência } \\
\text { resultante da miséria [...]. Que não esteja também } \\
\text { submetido ao medo da violência de um governo } \\
\text { contra o seu próprio povo" (BRASIL, 2019, p. 4). }\end{array}$ \\
\hline
\end{tabular}

Fonte: Elaboração própria a partir dos relatórios finais das conferências, 2021.

Percebe-se o avanço do debate que passa a incorporar uma atenção integral, preventiva e intersetorial para monitorar e combater a violência. Propostas que envolvem educação permanente da sociedade, capacitação de profissionais, construção de serviços específicos, diálogo com outras políticas públicas, o reconhecimento que a violência atinge de diferentes formas determinados grupos da sociedade, entre outros aspectos, são marcos deliberativos que estão em acordo com as normativas internacionais e nacionais e dão terreno sólido 
para a violência se constituir como problema de saúde pública.

No entanto, chama atenção a repetição das mesmas propostas ao longo das conferências do período analisado, o que pode indicar a sua não efetivação. Esta afirmação requer maior aprofundamento analítico com o estudo da incorporação das diretrizes no planejamento governamental e na execução orçamentária, como exemplo, a investigação e cruzamento dos relatórios finais com o Plano Plurianual (PPA), Lei de Diretrizes Orçamentária e Lei Orçamentária Anual (LOA). Também é interessante notar que os aspectos conjunturais que conformam a cena política e econômica influenciam as Conferências e a amplitude das deliberações. Não à toa, 2015 registra uma Conferência com relatório enxuto e que não incorpora grandes temas sociais como a violência, o que pode-se entender como reflexo da crise política que o país registrava.

À guisa de conclusão, percebe-se que a abordagem sobre a violência nas Conferências depende do embate entre os sujeitos políticos e projetos sociais em disputa, bem como dos determinantes estruturais e conjunturais que constituem o período sócio-histórico. Os avanços são inegáveis, mas a permanência, fortalecimento e aprofundamento do debate necessita de mais ações, políticas e sujeitos que compreendam que o enfretamento da violência requer a defesa de um sistema de saúde amplo, público e de qualidade, democrático e participativo.

\section{Referências}

BARDIN, Laurence. Análise de conteúdo. Lisboa: Ed. 70, 2009.

BEHRING, Elaine Rosseti. Brasil em contra-reforma: desestruturação do Estado e perda de direitos. São Paulo: Cortez, 2003.

BRASIL. 11 a Conferência Nacional de Saúde, Brasília 15 a 19 de dezembro de 2000: o Brasil falando como quer ser tratado: efetivando o SUS: acesso, qualidade e humanização na atenção à saúde com controle social: relatório final / Ministério da Saúde, Conselho Nacional de Saúde. Brasília: Ministério da Saúde, 2001.

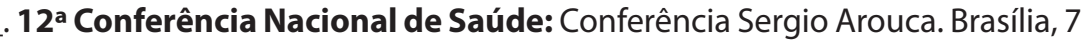
a 11 de dezembro de 2003: relatório final / Ministério da Saúde, Conselho Nacional de Saúde. Brasília: Ministério da Saúde, 2004. 
. Conselho Nacional de Secretários de Saúde. CONASS Documenta n. 15. Violência: uma epidemia silenciosa. Brasília: CONASS, 2007.

. Diretrizes aprovadas nos Grupos de Trabalho ou na Plenária Final: por ordem de votação nos eixos temáticos. Brasília: Ministério da Saúde, 2015.

. Lei $\mathbf{n}^{\circ} \mathbf{8 0 8 0}$, de 19 de setembro de 1990. Dispõe sobre as condições para a promoção, proteção e recuperação da saúde, a organização e o funcionamento dos serviços correspondentes e dá outras providências. Disponível em: http://www. planalto.gov.br/ccivil_03/leis//8080.htm. Acesso em: 28 Nov. 2020.

. Lei $\mathbf{n}^{\circ} \mathbf{8 1 4 2}$, de 28 de dezembro de 1990. Dispõe sobre a participação da comunidade na gestão do Sistema Único de Saúde (SUS) e sobre as transferências intergovenamentais de recursos financeiros na área da saúde e dá outras providências. Disponível em: http://www.planalto.gov.br/ccivil_03/leis/l8142.htm. Acesso em: 28 Nov. 2020.

Política Nacional de Redução da Morbimortalidade por Acidentes e Violências: Portaria MS/GM nº 737 de 16/5/01. Brasília: Ministério da Saúde, 2002.

Relatório Final da 13a Conferência Nacional de Saúde: Saúde e Qualidade de vida: políticas de estado e desenvolvimento/Ministério da Saúde, Conselho Nacional de Saúde. - Brasília: Editora do Ministério da Saúde, 2008.

CERQUEIRA, Daniel et al. Análise dos custos e conseqüências da violência no Brasil. Texto para discussão no 1284. Brasília: IPEA, junho de 2007.

CNS. Conselho Nacional de Saúde. 16a Conferência Nacional de Saúde: democracia e saúde. 2020.

. Documento Orientador de apoio aos debates da 15 ${ }^{\text {a }}$ Conferência Nacional de Saúde. Brasília, 15 de maio de 2015. Disponível em: https://conselho. saude.gov.br/web_15cns/docs/05mai15_Documento_Orientador_15CNS.pdf. Acesso em: 29 Nov. 2020.

CONCHA-EASTMAN, Alberto; MALO, Miguel. Da repressão à prevenção da violência: desafio para a sociedade civil e para o setor saúde. Ciência \& saúde coletiva, v. 11, p. 1179-1187, 2008. Disponível em: <http://www.scielo.br/scielo.php?script=sci_ arttext\&pid=S1413-81232006000500008\&lng=en\&nrm=iso $>$. Acesso em:01 Out. 2020. 
DRAIBE, Sônia Maria. As políticas sociais e o neoliberalismo. Revista USP, n. 17, p. 86-101, 1993.

GOHN, Maria da Glória. Conselhos gestores e participação sociopolítca. 4a ed. São Paulo: Cortez, 2011.

GUIZARDI, Francini Lube et al. Participação da comunidade em espaços públicos de saúde: uma análise das Conferências Nacionais de Saúde. Physis: Rev. Saúde Coletiva. Rio de Janeiro, 14(1): 15-39, 2004.

IPEA - Instituto de Pesquisa Econômica Aplicada; FBSP - Fórum Brasileiro de Segurança PÚBLICA. Atlas da violência 2019. Brasília, Rio de Janeiro, São Paulo: IPEA/FBSP, 2019.

KRUG, Etienne G. (Ed.). Organização Mundial de Saúde. Relatório mundial sobre violência e saúde. Genebra: OMS, 2002.

LAVILLE, Christian; DIONNE, Jean. A construção do saber: manual de metodologia da pesquisa em ciências humanas. Porto Alegre: Editora Artes Médicas; Belo Horizonte: Editora UFMG, 1999.

MINAYO, Maria Cecília de Souza. A inclusão da violência na agenda da saúde: trajetória histórica. Ciência \& saúde coletiva, v. 11, suppl., p. 1259-1267, 2006 a. Disponível em: <http://www.scielo.br/scielo.php?script=sci_arttext\&pid=S141381232006000500015\&lng=en\&nrm=iso >. Acesso em: 01 Out. 2020.

. Violência e saúde. Rio de Janeiro: Editora Fiocruz, 2006b.

;SOUZA, Edinilsa Ramos de. Violência e saúde como um campo interdisciplinar e de ação coletiva. História, ciência, saúde - Manguinhos. Rio de Janeiro, v. 4, n. 3, p. 513-531, 1997. Disponível em: <http://www.scielo.br/scielo.php?script=sci_ arttext\&pid=S0104-59701997000300006\&lng=en\&nrm=iso >. Acesso em: 01 Out. 2020.

OLIVEIRA, Dennis de. A violência estrutural na América Latina na lógica do sistema da necropolítica e da colonialidade. Revista Extraprensa, v. 11, n. 2, p. 39-57, São Paulo, jan/jun. 2018.

OPAS - Organização Pan-Americana de Saúde; OMS - Organização Mundial de Saúde. Repercussão da violência na saúde das populações americanas. $C D$ 
44/15. Washington: OPAS/OMS, 2003.

RICARDI, Luciani Martins et al. As Conferências Nacionais de Saúde e o processo de planejamento do Ministério da Saúde. Revista saúde debate, v. 41, n. 3, p. 155170, 2007.

SAYD, Jane Dutra et al. Recursos humanos nas Conferências Nacionais de Saúde (1941-1992). Physis: Revista de Saúde Coletiva, vol. 8, n. 2, p. 165-195, 1998.

SCHRAIBER, Lilia Blima; D'OLIVEIRA, Ana Flávia P L; COUTO, Márcia Thereza. Violência e saúde: estudos científicos recentes. Revista Saúde Pública, São Paulo, v. 40, n. spe, p. 112-120, 2006. Disponível em: <http://www.scielosp.org/scielo. php?script=sci_arttext\&pid=S0034-89102006000400016\&lng=en\&nrm=iso $>$. Acesso em: 01 Out. 2020.

SEGRE, Marco; FERRAZ, Flávio Carvalho. O conceito de saúde. Revista de Saúde Pública, São Paulo, v. 31, n. 5, p. 538-542, 1997. Disponível em: <http://www. scielosp.org/scielo.php?script=sci_arttext\&pid=S0034-89101997000600016\&lng $=$ en\&nrm=iso $>$. Acesso em: 01 Out. 2020.

SILVA, Berenice Temoteo; LIMA, Isabel Maria Sampaio Oliveira. 15 Conferência Nacional de Saúde: um estudo de caso. Saúde Soc. São Paulo, v. 28, n. 3, p. 97-114, 2019. Disponível em https://www.scielo.br/scielo.php?pid=S010412902019000300097\&script=sci_abstract\&tlng=pt. Acesso em 09 Mar. 2021.

SOUZA, Clóvis Henrique Leite et al. Conferências típicas e atípicas: um esforço de caracterização do fenômeno político. In: AVRITZER, Leonardo; SOUZA, Clóvis Henrique Leite. Conferências nacionais: atores, dinâmicas participativas e efetividades. Brasília: IPEA, 2013. p. 25-52.

SOUZA, Edinilsa Ramos de et al. Tendências da produção científica brasileira sobre violências e acidentes na década de 1990. In: MINAYO, Maria Cecília de Souza; SOUZA, Edinilsa Ramos de (Org). Violência sob o olhar da saúde: a infrapolítica da contemporaneidade brasileira. Rio de Janeiro: Editora Fiocruz, 2003. p. 40-82.

TOFANI, Luís Fernando Nogueira; CARPINTERO, Maria do Carmo Cabral. $3^{a}$ Conferência Municipal de Saúde de Várzea Paulista: a participação da sociedade no processo de priorização e compromisso político. Saúde soc. São Paulo, v. 21, supl. 1, p. 244-252, 2012. Disponível em https://www.scielo.br/scielo. 
php?pid=S0104-12902012000500021\&script=sci_abstract $\&$ tlng=pt. Acesso em 27 Nov. 2020.

Recebido: 30/11/2020

Aceito: 22/02/2021 